\title{
The Effect of Macroeconomic Variables On the Saudi Stock Market
}

\author{
Amani Mohammed Aldukhail \\ MSc in Finance Student, Graduate Programs, \\ College of Business and Economics. Qassim University
}

\begin{abstract}
This study aimed at exploring the effect of macroeconomic variables on the activity of the Saudi stock market for the period 1997-2017. Macroeconomic variables were: GDP, interest rate on time deposits, inflation rate. The variables of the Saudi stock market activity were: stock price index, market value of shares, value of traded shares. To achieve this objective, the researcher used the ARDL model for the self-regression of the lagged distributed time gaps. The most important results of the research are: The effect of macroeconomic variables on the performance indicators in the Saudi stock market is not important in the short term and is statistically significant in the long term according to the proposed models, so investors in this market can rely on macroeconomic variables in Predict the movement of the stock market and predict long-term profits and losses.
\end{abstract}

Keywords: Macroeconomics, Saudi Stock Market, Cointegration Relationship, ARDL Model, Bounding Cointegration test, long-term Relationship, short-term Relationship, ECT (error correction term).

\section{Background of the study}

\section{INTRODUCTION}

Financial markets are an important tool in the financial sector, which is the backbone of the ongoing economic development process, and the nature of the relationship between capital markets and economic growth is a reciprocal relationship between the two directions because the financial market does not operate in isolation from the outside world but affects and is influenced by Many of which are:

- Gross Domestic Product (GDP): This indicator measures the total value added by economic agents over a period of time. The increase in this indicator provides opportunities and financial investment alternatives.

- Deposit rate: the rate paid by commercial banks on demand deposits, time deposits or savings deposits. The increase in the interest rate on time deposits is expected to adversely affect Saudi Stock Exchange indices.

- Inflation rate: This indicator measures the rise in the general level of prices, expressing the value of money at a certain point in time, and the change in it can affect the expected return of the security.

The indicators that measure the performance of the financial market in order to know their degree of maturity and progress, and at the same time reflect their performance. The performance of the financial market is affected by these instruments, some of which may have a positive effect and the other have a negative effect on their performance, which causes fluctuations in their indices.

The main indicators of the performance of the financial market are:

- Stock price index: A measure that measures the overall performance of a market and consists of the prices of a group of shares that are supposed to be used as a measure of 
the general movement of the stock market and is expected to be positively affected by macroeconomic variables.

- Market Value of Shares: This indicator refers to the total value of securities listed in the market and to determine the degree of development of the stock market and is measured by dividing the market value of the listed shares on the gross domestic product. This rate reflects its level of activity. The level of the market both in terms of increasing the number of shares and the number of listed companies, or the rise in prices, which is a reflection of the broad volume of financial transactions.

- Value of Shares Traded: means the value of traded shares and bonds at different prices over a period of time and reflects the total value of securities traded over a period of time, measured by dividing the value of total shares traded on GDP, which refers to the volume of transactions in the stock market As for the size of the national economy, this indicator reflects the level of liquidity in the national economy in general. We may find that the volume of trading is small, but the market may be large, so the volume must be used and supplemented by the market value index in order to obtain sound information.

Positive macroeconomic variables are expected to be positively affected.

From here, our study begins to determine the effect of macroeconomic variables on the performance of the financial market To determine the degree of influence of each of the variables studied in order to arrive at a realistic model that governs the mutual influences between the position of financial markets and economic performance. In our study we focused on the most important indicators that can reflect the degree and maturity of the market, and we used An Autoregressive Distributed Lag (ARDL) modeling.

\section{The objective of study}

The objective of this study is to clarify the effect of the combined integration of macroeconomic variables (GDP, deposit rate, inflation rate) on the performance indicators of the financial market (stock price index, market value of shares, value of traded shares) in Saudi Arabia over the long term And the short term using the ARDL and ECM models, and make recommendations for those who make the Saudi economic policy according to the experimental results of this study.

\section{Research questions}

From the above, the following main problem can be raised:

Are there any statistically significant effects of the macroeconomic variables on the performance indicators of the Saudi stock market in the long and short term?

To answer the problem, we have formulated the following sub-questions:

1- What is the relationship between the indicators of the performance of the Saudi stock market (dependent variables) and variables of Saudi macroeconomics (independent variables) reverse or positive and what is its strength?

2- Is it possible to predict the level of variables of performance of the Saudi stock market (dependent variables) depending on Saudi macroeconomic variables (independent variables) in the long and short term?

\section{The scope of the study}

The objective limit: The impact of the variables of the Saudi economy on the performance of the Saudi stock market.

Spatial limit: Saudi stock market 


\section{LITERATURE REVIEW}

Several studies have been conducted to ensure that macroeconomic variables have a positive or other effect on the stock market index. A number of guides have been reviewed by several researchers in this chapter in order to obtain sufficient and better knowledge of the impact of stock market performance indicators on macroeconomic variables in both developed and developing economies.

The study by Acikalin and Aktas \& Unal (2008) aims to determine the relationship between returns on the Istanbul Stock Exchange (ISE) and Turkey's macroeconomic variables. Using VIA and VECM in a quarterly data set, there are stable long-term relationships between the ISE and four macroeconomic variables, GDP, exchange rate, interest rate, and current account balance. Through causal tests, the study found that there are one-way relationships between macro and ISE indicators. This, in line with current literature, changes in GDP, foreign exchange rate and current account balance have an impact on the ISE index. However, contrary to expectations, the changes in the stock market index will affect interest rates.

The study AL-Shogeathri, (2011), examines the long-term and short-term relationships between Saudi stock market returns and eight macroeconomic variables. The ability of these variables to predict the level and volatility of the Saudi stock market was verified. There is a wide range of vector self-regression models (VARs) as well as estimated and interpreted GARCH conditional modulation models (GARCH). The test of AJohansen-Juselius co-operation indicates a long-term positive correlation between the Saudi stock price index and M2 money supply, bank credit, the price of oil, and a long-term negative relationship with M1 money supply, short-term interest rate, inflation, and the US stock market. The vector error correction model (VECM) suggests significant short-term causal relationships between Saudi stock market returns and money supply and inflation. VECM also finds a long-term causal relationship between macroeconomic variables in the system. The estimated speed of adjustment suggests that the Saudi stock market is converging with this balance in half a year. Granger's causality tests show no causal relationship between Saudi stock market returns and the exchange rate. Analysis of the driving response function does not show any significant relationship between the returns of the Saudi stock market and macroeconomic variables. Analysis of the error variance indicates that $89 \%$ of the variance in Saudi stock market returns is due to its own shock, which means that the returns of the Saudi stock market are largely independent of the macroeconomic variables in the system. Finally, the GARCH-X model suggests that there is a significant correlation between the volatility of Saudi stock returns and macroeconomic movements in the short term.

In the study Abedallat \& Shabib (2012), The effect of macroeconomic variables such as change in investment and Gross Domestic Product (GDP) was examined as independent variables and the Amman Stock Exchange index developed as a variable for the period from 1990 to 2009. To analyze the above relationship, multiples were used. The macroeconomic indicators (investment and GDP) The Amman Stock Exchange index, as well as between each of them separately and the index of the stock market, which means that the development of prices in the Amman Stock Exchange is affected by the movement of these variables, and the impact of both variables on the movement of the Amman Stock Exchange. Moreover, they found that the effect of the change in investments was greater than the impact of the change in GDP on the ASE.

The study Kumar \& Puja (2012), investigates the relationships between the Indian stock market index (BSE Sensex) And five macro-economic variables, the index of industrial production, the wholesale price index, the money supply, and treasury bills and exchange rates 
during 1994: 04-2011: 06. The Johansen Model of Joint Integration and Error Correction in Vector Control was applied to explore the long-term equilibrium relationship Long between the stock market index and macroeconomic variables. The analysis reveals that macroeconomic variables and the stock market index are complementary, and therefore there is a long-term equilibrium relationship between them. It is also noted that stock prices are linked to a positive relationship with money supply and industrial production, but they are linked to a negative relation to inflation. There is little impact on the exchange rate and the short-term interest rate in determining stock prices. In a causal sense, the macroeconomic variable causes stock prices in the long term but not in the short term. There is a two-way causal relationship between industrial production and stock prices, while there is a one-way causality from money supply to stock price and stock price to inflation and interest rates to stock prices.

The objective of the study Ayako (2014) is to determine the long-term effects of local macroeconomic variables on the EU Stock Exchange index of 20 stocks using joint integration tests, Gangerger causal tests, and VECM. The study uses the data for the monthly time series covering the period from 1993 to 2013. The data set included the 91-day Treasury bills in Kenya, the inflation rate, the 20 NSE index, the EU inflation rate, the M3, the Industrial Production Index , And FTSE 100 (UK). The ADF tests reveal that the variables were not constant. I am (1) at their levels, but fixed in their first difference. Johansen-Juselius's cointegration test shows that variables have a long-term relationship. Integrated. Granger's causal tests reveal one-way causal relationships ranging from 91 days of interest rate in Kenya and from the European Union M3 to the 20 NSE. Similarly, the Nanger 20-Granger index is causing inflation in the European Union and the Industrial Production Index. VECM results show that the 91-day T-bill has a negative and significant impact on the NSE 20 - short-term equities. M3 in the European Union, the industrial production index, the FTSE 100 index has a positive and significant impact on the NSE 20 index - stocks in the short term. In the long run, the EU industrial production index and the T-bill rate in Kenya for 91 days have a positive impact on the NSE 20 index. By contrast, the M3 index and the FTSE 100 index in the EU have a negative impact on the NSE 20 index. In general, the NSE joins its long-term balance in 36 months. In light of these results, NSE investors should take into account changes in macroeconomic variables in Kenya and the EU in their investment decisions.

The present paper Ray \& Sarkar (2014) attempts to explore the dynamic relationship between the stock market and selected macroeconomic variables at record levels, in India, for the period 1991: 1 to 2008: 04. The results of the study showed that long- In terms of production and exchange rate, and is negatively correlated with short- and long-term interests, monetary supply and inflation. The results of the analysis of causality and innovation indicate that the stock market affects economic activities, particularly industrial activities, and the market is expected to be more sensitive to shocks itself during the expected period of study.

The study Kalyanaraman \& Tuwajri (2014), examines the long-term relationship between five macroeconomic variables, CPI, industrial production, money supply, exchange rate, oil prices and the S \& P 500 index. Stock Index. Time series analysis is applied using monthly data from January 1994 to June 2013. The application of the Johansen Co-ordination Test finds a longterm relationship between the selected variables. All macroeconomic variables were found to affect stock prices. S \& P 500 does not affect Saudi stock prices. The vector error correction model illustrates the long-term causality of explanatory variables to stock prices. Short-term causal testing finds a causal link between stock prices and oil prices. The impulse response function shows that shocks to industrial production drive stock prices higher while consumer price indices are hit by them. Analysis of variance shows that historical stock prices are the main drivers of Saudi stock prices. This means that the Saudi stock market follows a weak form 
of market efficiency. The results of this paper have important implications for investors in the Saudi stock market.

The study Venkatraja.B (2014), examines the relationship between the performance of the Indian stock market (BSE Sensex) and five macroeconomic variables, namely the index of industrial production, the wholesale price index, the gold price, the foreign institutional investment and the real effective exchange rate during the period from April 2010 to June 2014 using the monthly data. The necessary data is collected from secondary sources. The main objective of this paper is to study the effect of selected macroeconomic fundamentals on BSE Sensex performance. Multiple regression techniques are used for this purpose. To start the formal statistical investigation, the Durbin-Watson test is applied and no evidence of automatic correlation between the independent variables was found and the dataset was provided for further testing. Summary The regression model supports the strong common effect of independent variables on Sensex. Of the results, $82 \%$ of the variation in Sensex appears to be illustrated by the five selected macroeconomic factors. The wholesale price index, the index of industrial production, foreign institutional investment and the real effective exchange rate have a high degree of positive impact on Sensex. Sensex was also found to be adversely affected by changes in the price of gold. Moreover, among the five variables, the coefficients of all variables except for the industrial production index are statistically significant. This leads to the conclusion that inflation, the influx of foreign institutional investments, the exchange rate and the price of gold have a major impact on the performance of the Indian stock market.

The study Muazu \& Alhassan (2014), Based on data from September 2000 to September 2010, this study examines the effects of macroeconomic variables on stock market returns through the use of Johanssen's multivariate approach to integration and the vector error correction model. The study provides evidence of a long-term relationship between macroeconomic variables and stock returns. The test of the causal relationship was not able to prove the causal relationship of any direction between macroeconomic variables and stock prices and that previous literature that found the causal relationship between this chain may be misleading. Results from impulse response and dissolution functions show that among macroeconomic variables, inflation, cash supply and exchange rate shocks do not account for a large proportion of the variance error in stock returns but their effects persist over a long period of time.

The study Kirui et al. (2014), seeks to assess the relationship between GDP, treasury bills, exchange rate, inflation, and stock market returns at Nairobi Securities Limited. The study identifies the response of stock returns to shock in both macroeconomic variables. The effect of the changes in both the macroeconomic variable on the volatility of stock returns on the Nairobi Stock Exchange Limited is determined. The two-step Engle-Granger method is used to establish a common correlation between stock returns and macroeconomic variables. The conditional heterogeneity model uses the generalized threshold (TGARCH) to capture the effects of lifting and continuous oscillation in the NSE. Quarterly data for published time series from 2000 to 2012 are obtained from the Central Bank of Kenya, the National Statistics Office of Kenya. The empirical results of the regression model suggest that the exchange rate shows a significant correlation with equity returns. For one percentage point of the increase in local currency depreciation, the model foresees a drop in stock returns of 1.4 per cent. Gross domestic product, inflation and the rate of Treasury bonds were weak. The effects of the standard deviation shock on both the macroeconomic variable on stock returns indicate that the shock in the exchange rate is negative but eventually returned to equilibrium. The results of the TGARCH model for the exchange rate, GDP and treasury bond price indicate that the impact of the news is asymmetrical and there are leverage effects. There is no fluctuation in stability between all macroeconomic variables. 
The study Samontaray et al. (2014), examines the three important factors affecting the returns on the Saudi stock market (TASI) based on the Saudi economy variables for the Saudi economy. The dependent variable is the Saudi index traded. The three independent variables that were considered in this study are WTI oil, Saudi exports and PE ratio. The correlation analysis revealed that Saudi exports and PE were found to be significantly associated with TASI at 1\% of importance while Oil WTI and TASI were significantly associated with $5 \%$. The regression analysis of the data step revealed that multiple regression models are important at the $1 \%$ level and the variable PE rate was the most important determinant of the TASI index followed by Oil WTI and Saudi exports. In addition, the three independent variables explain about 93\% of the variation in TASI Last Price.

The study Aigbovo \& Izekor (2015), Examines the effect of six macro-economic variables exchange rates, inflation, interest rates, cash supply, industrial production index and international oil prices on Nigeria's stock market index. The period of this study is between January 2000 and December 2010. Using the enhanced DUCI root test, the core chain is tested as non-stationary at the first level but fixed at the first difference. The use of co-operation test Johansen indicates that macroeconomic variables and stock index are complementary. This means a long-term relationship between the specific macroeconomic variables and the stock index in Nigeria. The OLS and ECM also revealed that inflation, interest rate, cash supply, industrial production index and oil prices affect the stock market index both in the short and long term.. Granger's test of the causal relationship reveals one-way and two-way relationships. There is a two-way causal relationship between the price of oil and the stock index. Money supply and stock market index While the one-way causality operates from industrial production to the stock market index; interest rates were found for the stock index. Thus, share price expectations through changes in macroeconomic variables become possible and can help in economic forecasting, planning and growth. The main conclusion of this study is that macroeconomic variables cannot be ignored in accounting for the dynamics of stock market behavior in Nigeria. Therefore, we recommend adopting appropriate macroeconomic policies that support the stock market index (the proxy for stock prices), which in turn will stimulate the growth of the stock market in Nigeria.

The research paper Mu'tasem \& Naomie (2016), identifies these factors that affect the performance of the Saudi stock market, known as Tadawul, while the index is called "Tadawul All Shares" (TASI). Movements in the stock market can be very volatile, and sometimes movements in stock prices may seem separate from economic factors. However, there are some key factors that have a strong impact on the movement of stock prices and the stock market in general. In this paper, we discuss the factors affecting the Saudi stock market, where the main factors have been identified, along with their sub-factors. It can be seen that in general, demand will be greater on stocks when investors have the potential to earn more profits. Therefore, the factors that make more profitable companies tend to cause stock markets to rise.

The main objective of the study P R Venugopal \& K Sudha (2017), is to assess the relationship between the selected macroeconomic variables: exchange rate, money supply (M3), exchange rate, gold and silver prices, forex reserves, consumer price index as an alternative to inflation, stock prices from 30 companies Form the basis for the main measure of the Indian economy, the Bombay Sensex Stock Exchange (BSE30). In an attempt to understand the degree of influence of some macroeconomic variables on stock prices and vice versa. In this study, use the time series method. The required data is collected from reliable secondary sources such as RBI, BSE and other international sites. The study time period from January 2000 to August 2017, the expected results are extracted using the OLS method and the Granger causal test. Call 
rate, exchange rate and Forex reserves are found to have a significant impact on the Indian BSE 30 index.

The study Amata (2017), reveals the relationship between macroeconomic variables and stock market volatility in Kenya. Specifically, the study examines the direct relationship between each of the four specific macroeconomic variables: interest rates, inflation rate, foreign exchange rate, GDP, and stock market volatility. The study also explores the moderate impact of investor grazing behavior on the direct correlation between selected macroeconomic variables and stock market volatility, The study adopts a descriptive research design targeting all companies listed on the Nairobi Stock Exchange from January 2001 to December 2014. The study uses secondary data on interest rate, exchange rate, inflation rate and GDP, covering 14 years. Data are obtained from the Kenya National Bureau of Statistics and the Central Bank of Kenya. Data on stock prices and market indices are obtained from Nairobi Securities. The volatility of the stock market is measured by calculating the standard deviation of the Nairobi Stock Exchange and the monthly returns over the 14-year period. The study used the marketwide herd index, which is calculated using the standard deviation (CSSD) method. The data is analyzed using E-views version 8. The study employs both correlation and regression analysis. The correlation analysis results found that there is a significant correlation between all selected macroeconomic variables and stock market volatility. However, when the long-term and short-term causal relationship was tested using the VECM and the causal relationship test with Granger, the study found that the interest rate and inflation amplifier were causing shortand long-term stock market volatility in Kenya, while GDP The total and the exchange rate have no direct causal relationship with stock market volatility. The study also shows that investor grazing behavior has no direct causal relationship to stock market volatility. However, investor grazing behavior significantly reduces the relationship between the exchange rate and volatility of the stock market on the Nairobi Stock Exchange. The results of the study are limited to the selected macroeconomic variables and their methods of measuring and analyzing the relationship. Further studies are recommended to investigate other macroeconomic variables in order to understand their impact on the volatility of the Kenyan stock market, the study recommends a strict monetary policy and control of factors that contribute to changing inflation and interest rates which the study found to be key variables contributing to stock market volatility.

The study Aggarwal \& Saqib (2017), A study of the effect of changes in selected macroeconomic variables on the Indian stock market (NEVTI 50 index) is the main objective of this study. The relationship between these variables was estimated. The multivariate regression model calculated using a standard linear square method was used. The time period examined was 2001-2016 and all tests were conducted based on monthly data. Based on the estimated regression coefficients and $t$ statistics, it was found that the 50 index is heavily influenced by US GDP, S \& P, gold prices, India's full selling price, its financial deficit, IPI and exchange rate.

The study by Jamaludin et al. (2017), The study examined the effect of macroeconomic variables (inflation, money supply (MS) and exchange rate (ER) on traditional and Islamic stock market returns in the three selected ASEAN countries (Singapore, Malaysia, Indonesia). 2015. When applying square plate regression techniques, the results show that stock market returns are significantly affected by ER and inflation. MS is found to be slim. The results of this study also show that inflation is more influential and is inversely related to the returns of the stock market. Based on this result, there is a need to adjust monetary policy to ensure that inflation is set at a low level because the results will be able to impact the strengthening of the capital market in ASEAN countries Selected. 
The study Saleh In'airat (2018), examines the effect of dividend distributions as an internal factor, and oil prices as an external factor on stock market prices in oil-producing economies. The study sample was the data of 40 companies listed on the Saudi Stock Exchange during the period 2011 to 2015 . The data regression model was used to analyze the data and to verify the potential relationships between the variables identified. Dummy variables were used to capture the sectoral effect on the market price of stocks. The results of the study provided empirical evidence supporting the view that dividends are relevant to the interpretation of the market price of shares, particularly listed companies in the Saudi stock market. The results revealed a significant positive impact of oil prices per week, and the sector in which a company belongs can play a role in determining the price of the company's shares.

The study Ndlovu et al. (2018), assesses the effect of macroeconomic variables: inflation (INF), money supply growth (M3), interest rates (IR) and the exchange rate of the US dollar (EX) using quarterly data from 1981 to 2016 Q4 on the price Arrow, Johannesburg share South Africa exchange. The study used joint correlation tests, vector error correction model, dissolution of variance, and pulse response function to understand the relationship between these variables. In the long run, interest rates, cash supply and inflation give a positive relationship to the share price while the exchange rate has a negative impact on stock prices. Unidirectional causation was found to operate from exchange rates and interest rates to the share price as well as interest rates and exchange rates having a causal link to money supply. Contrast analysis has shown that stock price shocks represent the majority of changes per se for all periods during the short and long term while the causal shocks in stock prices and exchange rate shocks enhance their impact on changes in themselves, as well as the impulse response function. Arrow.

In the study Khan \& Khan (2018), by analyzing the monthly data from May 2000 to August 2016, the effect of various macroeconomic variables on stock prices in Pakistan was determined and all variables were fixed at the first difference. Therefore, the ideal ARDL approach was applied to the restricted test to verify the short- For the integration of macroeconomic variables on stock prices, the results indicate that long-term stock prices on the Karachi Stock Exchange are heavily affected by money supply, exchange rate and interest rates. In the short term, all variables are insignificant except for the exchange rate, which is negatively integrated with stock prices. You must be vigilant while changing money supply in the market because excess money supply may affect investment as well as the stock market. The regulator should keep the interest rate relatively low to encourage economic activities, improve the external economic environment through the rule-based exchange rate policy and avoid discretionary measures.

\section{Type of study}

\section{METHODOLOGY AND DATA}

Many time series are non -stationary and in general if the series is nonstationary, it is not possible to use traditional econometric techniques since models with nonstationary variables might lead to a problem of spurious regression. For this reason, it is important to establish the stationary properties of the series, cointegration implies the existence of meaningful long run equilibriumTo achieve the objectives of the study, we adopted the autoregressive distributed lag (ARDL) modelling Which developed by Pesaran and Pesaran (1997), Pesaran and Smith (1998), and Pesaran et al.. (2001), the ARDL modelling approach has several advantages in comparison with other single cointegration procedures, and result from the ability to estimate the long and short-run parameters of the model simultaneously, while avoiding the problems posed by non-stationary time series data. In addition, this approach does not require a prior determination of the order of the integration amongst the variables, unlike other approaches 
which require that the variables in the time series are integrated of the same order. Furthermore, the ARDL procedure is the more statistically significant approach to determine the cointegration relation in small samples, besides the ARDL procedure allows that the variables may have different optimal lags.

The study used the quantitative method using EVIEWS.10 program, the study used annual data from 1997 to 2017.

\section{The Research Model}

The general formula of the model consists of a variable $(\mathrm{Y})$ and $(\mathrm{K})$ and the explanatory variables $(\mathrm{X} 1, \mathrm{X} 2 \ldots \mathrm{XK})$ form the form $(\mathrm{P}, \mathrm{q} 1, \mathrm{q} 2 \ldots \mathrm{qK})(\mathrm{ARDL})$ as follows:

$$
\begin{gathered}
\Delta \mathrm{Y}_{\mathrm{t}}=\mathrm{c}+\mathrm{B}_{1} \mathrm{Y}_{\mathrm{t}-1}+\mathrm{B}_{2} \mathrm{X}_{1 \mathrm{t}-1}+\mathrm{B}_{3} \mathrm{X}_{2 \mathrm{t}-1}+\ldots+\mathrm{B}_{\mathrm{k}+1} \mathrm{X}_{\mathrm{kt}-1}+\sum_{\mathrm{i}=1}^{\mathrm{p}-1} \lambda_{1 \mathrm{i}} \Delta \mathrm{Y}_{\mathrm{t}-\mathrm{i}}+\sum_{\mathrm{i}=0}^{\mathrm{q}_{1}-1} \lambda_{2 \mathrm{i}} \Delta \mathrm{X}_{1 \mathrm{t}-\mathrm{i}} \\
+\sum_{\mathrm{i}=0}^{\mathrm{q}_{2}-1} \lambda_{3 \mathrm{i}} \Delta \mathrm{X}_{2 \mathrm{t}-\mathrm{i}}+\ldots+\sum_{\mathrm{i}=0}^{\mathrm{q}_{\mathrm{k}}-1} \lambda_{(\mathrm{k}+1) \mathrm{i}} \Delta \mathrm{X}_{\mathrm{kt}-\mathrm{i}}+\mu_{\mathrm{t}} \ldots . .(\mathbf{1})
\end{gathered}
$$

$\Delta$ : First differences. C: Fixed limit. $\mu$ t: Random error limit B: Long-term relationship parameters. $\boldsymbol{\lambda}$ : Short-term relationship parameters.

(P, q1, q2....qK): represent the deceleration periods for variables $(\mathrm{Y}, \mathrm{X} 1, \mathrm{X} 2 \ldots \mathrm{XK})$ respectively. The ARDL model will be used for three models where the model is formed in each case of one of the variables of the performance of the Saudi stock market as a dependent variable, and macroeconomic variables to be reflected on that variable as independent variables, the models are:

1. The first model: The index of stock prices is the indicator of market activity.

2. Second model: Market value is the indicator of market activity.

3. The third model: The volume of trading is the indicator of market activity.

\section{Dependent variable:}

$y_{1}=$ Stock Price Index. $y_{2}=$ Market value of shares. $y_{3}=$ Volume of shares traded.

\section{Independent variables:}

$X_{1}=$ Gross domestic product. $X_{2}=$ Deposit Rates. $X_{3}=$ Inflation rate.

\section{Hypotheses}

The research hypotheses in answering the research questions about the significance of the independent variables included in the regression model on the dependent variable were summarized as follows:

- H1: Macroeconomic variables have a statistically significant effect on the performance indicators of the financial market.

- H2: The relationship between the macro variables and the indices of the Saudi stock market is a positive relationship.

\section{Data collection method}

Source of data: Data were collected from the Saudi stock market in general from the Tadawul website, in addition to the official information issued by the Saudi Arabian Monetary Agency within the study period 1997 until 2017. 


\section{Population and Study Sample}

The study population consists of all the Saudi macro-economic activities through a series of three main indicators in addition to all the activities of the Saudi stock market represented by three indicators of the performance of the Saudi stock market during the period 1997 to 2017.

\section{Statistical analysis technique}

It was decided to use the ARDL model to determine the importance of Saudi macroeconomic variables on the proposed performance indicators for the Saudi stock market during the study period and the direction of the relationship of this effect, whether positive or negative. Data is processed using EVIEWS.10. Before starting the ARDL model, the root of the unit must be tested using several tests, the most important of which is the expanded DCI test to determine the stability of the time series. The ADF is applied using the OLS method through Estimation of one or more of the following models: - (Enders, 1995: 221)
A. Without a fixed limit and a time trend.
B. There is a fixed limit without a time trend.
C. There is a fixed limit and a time trend.
D. There is a fixed limit and a square slope.

This can be explained, respectively, as in the following equations:

$$
\begin{aligned}
& \Delta Y_{t}=B Y_{t-1}+\sum_{i=1}^{p} \lambda_{i} \Delta Y_{t-i}+u_{t} \\
& \Delta Y_{t}=a_{0}+a_{1} t+B Y_{t-1}+\sum_{i=1}^{p} \lambda_{i} \Delta Y_{t-i}+u_{t} \ldots . . .(3) \\
& \Delta Y_{t}=a_{0}+a_{1} t+B_{1} Y_{t-1}+\left(B_{2} Y_{t-1}\right)^{2}+\sum_{i=1}^{p} \lambda_{i} \Delta Y_{t-i}+u_{t}
\end{aligned}
$$

As:

$\Delta$ : The first difference. : a0, a1, B Parameters to be estimated. Y: The variable to be tested. P: The number of decelerations. ut: The random error element. $t$ : Time in the form of a general trend.

The resolution in the equations above is by comparing the value of $(\mathrm{t})$ calculated with the $\mathrm{t}$ critical value of the table after estimating the above formulas using the OLS method. If the absolute of t-calculated value is greater than the $t$-critical value ( $\mathrm{H} 0: \mathrm{B}=0$ ) is rejected and accept the alternative hypothesis (H1: B> 0), indicating the significance of the statistical parameter and the absence of the root of the unit, ie the time series of the studied variable is stable and vice versa. Is smaller than the $t$-critical value. We accept the null hypothesis $(\mathrm{H} 0: \mathrm{B}=$ 0 ) and reject the alternative hypothesis (H1: B> 0). So we test the stability of the first difference of the above equations and if they are unstable we repeat the test for the second difference (Dickey \& Fuller, 1981: 251). If the string is stable at the level, it is said to be a complete set of zero, ie I (0), but if the series is unstable at the level then the first difference is taken and the unit root is tested. (1), and if the second difference is achieved, the second group is said to be an integral group of the second class (Dickey \& Fuller, 1979: 433). Note that the critical values of $(t)$ to test the null hypothesis depend on the values of McKinnon.

After testing the degree of integration of model variables according to the ADF test, and to apply the approach of analysis of joint integration under the ARDL

\section{Model, five actions are required}

1. Examining the optimal delay periods for differences: We will conduct it through the Akaike Information Criterion (1973) and take the following formula:

$\operatorname{AIC}_{(\mathrm{P})}=\operatorname{Ln}\left[\operatorname{det}\left(\sum e\right)\right]+\frac{2 \mathrm{k}^{2} P}{T}$ 
2. Bounds Testing Approach: It is used to test the extent to which a long-term equilibrium relationship exists between the dependent variable and the explanatory variables in the model by means of the Wald test or the F test statistic, which has a non-standard distribution and is not dependent on factors such as sample size and inclusion of the trend variable in the estimate. The value of the F statistic is calculated according to the following formula:

$\mathrm{F}=\frac{(\mathrm{SSeR}-\mathrm{SSeu}) / \mathrm{M}}{\mathrm{SSeu} /(\mathrm{n}-\mathrm{k})}$

As follows:

SSER: The sum of the residual squares of the constrained model (the null hypothesis), ie, the absence of a long-term equilibrium relationship between variables lack of common integration between variables).

$\mathrm{H} 0: \mathrm{B} 1=\mathrm{B} 2=\ldots \ldots \ldots \ldots . . . . \mathrm{BK}+1=0$

SSeu: The sum of the residual boxes of the unrestricted model (the alternative hypothesis), that is, the existence of a long-term equilibrium relationship between variables (the existence of a common integration of variables).

$\mathrm{H} 1: \mathrm{B} 1 \neq \mathrm{B} 2 \neq \ldots \ldots \ldots \ldots . . . \neq \mathrm{BK}+1 \neq 0$

M: The number of parameters of the restricted model. n: Views (sample size). k: number of variables.

After the calculation of the value of $\mathrm{F}$ is compared to the value of the (F) tabular calculated by Pesaran et.al in 2001. Since the F test has a non-standard distribution, there are two critical values for it:

Minimum value: - Suppose that all variables are static at their original level, integrated from the rank I (0).

The value of the upper limit: Suppose that all variables are static in their first difference, that is, integrated from the first order I (1).

The decision shall be in three cases:

If the value of the calculated $F$ is less than the minimum value of the $C$ value, it accepts the null hypothesis that there is no common integration between variables (no long-term equilibrium relationship).

If the value of the calculated $F$ is greater than the value of the upper limit of the value (F) of the table, the alternative hypothesis that there is a common integration of the variables (long-term equilibrium relationship) is accepted.

If the value of the calculated $\mathrm{F}$ is between the upper and lower thresholds of the tabular value $(F)$, the results are not determined, which means that the decision cannot be made to determine whether the variables are mutually complementary.

The decision will be made on the basis of comparing the value of the calculated $\mathrm{F}$ with the minimum value of the $\mathrm{F}$ if the variables are integrated from the I (0) level. If they are integrated from the correct I (1), the decision will be made on the basis of Comparison of the value of the calculated (F) statistic with the value of the (F) tabular of the upper limit.

3. Estimating model parameters (ARDL) and error correction parameter (VECM):

After confirming a long-term equilibrium relationship between the dependent variable and the explanatory variables, the short and long term ARDL parameters and the VECM parameter are 
calculated according to equation (1) using the OLS method based on the number of specified delay intervals, And to determine the appropriate model is based on the method (Hendry), which moves from the year to the special, which is to cancel the variance variable first of any variable, the absolute values of the count $(t)$ of its own is insignificant, less than the correct one. Prior to the adoption and application of this model, the performance of this model should be ascertained by performing the following diagnostic tests: Lacrane randomized test of serial correlation between residues.

- Lagrange Multiplier Test of Residual \{Brush-Godfrey\} (BG)

- Test for the stability of conditional variation in self-regression Autoregressive Conditional Hetero scedasticity (ARCH).

- Test the normal distribution of random errors. Jarque Bera (JB).

- Test the suitability of the model in terms of the dummy shape. Ramsey (RESET)

- Linear Multiplication Test (Linear Multiplicity of Independent Variables). Multicolinearty Test.

4. Determination of the ARDL parameters: In order to ensure that the data used in this study are free of any structural changes in them, and to know the extent of stability and consistency of long term transactions with short term parameters estimates, one of the following tests can be used:

- Test the Cumulative Sum of Recursive Residual (CUSUM) Examine the cumulative total of the repeated residue boxes.

- Test the Cumulative Sum of Squares Recursive Residual (CUSUM SQ) These are two of the most important tests in this field, because they illustrate two important things: the stability and consistency of long-term parameters with short-term parameters, as well as the extent of any structural change in the data. According to these tests, the structural stability of the estimated parameters of the ARDL is achieved if the CUSUM and CUSUM SQ test graph within the critical limits (upper and lower limit) is at a significant level $(5 \%)$, The coefficients are not structurally stable if the test graph is outside the critical limits at a significant level (5\%).

5. Test the predictive performance of the estimated unrestricted error correction model: Since the quality of the estimated results depends on the predictive strength of the expected unrestricted error correction model, and for the standard predictions to be scientifically based and highly meaningful for the economic use, the model must be able to predict well within the estimation period.

To achieve this, several criteria are used to measure the predictive performance of standard macroeconomic models, the most important of which are:

- Theil Inequality Coefficient.

- Test the significance of the difference between the predicted value and the real value: This criterion is based on the Ex-Post Forecast in the test of the model's ability to predict, and this test depends on the test $(\mathrm{t})$.

- Jans coefficient: It measures the model's ability to predict during the sample period (n) and completes the post-sample period (m).

\section{Unit root for the time series (ADF) checksum}

In order to investigate the dormancy of the variables of the study, we used the extended unitwide (ADF) test, where the results were as shown in Table (1): 
Table (1): Unit root for the time series (ADF) checksum

\begin{tabular}{|c|c|c|c|c|c|c|}
\hline \multirow{2}{*}{ Variables } & \multicolumn{3}{|c|}{ level } & \multicolumn{3}{c|}{ first difference } \\
\cline { 2 - 7 } & Exogenous & $\begin{array}{c}\text { ADF } \\
\text { statistics }\end{array}$ & $\begin{array}{c}\text { Number } \\
\text { of delays }\end{array}$ & Exogenous & $\begin{array}{c}\text { ADF } \\
\text { statistics }\end{array}$ & $\begin{array}{c}\text { Number } \\
\text { of delays }\end{array}$ \\
\hline Y1 & Constant & $\begin{array}{c}-2.446 \\
(0.1425)\end{array}$ & 0 & Constant & $\begin{array}{c}-6.382 \\
(0.0001)\end{array}$ & 0 \\
\hline Y2 & Constant & $\begin{array}{c}-1.4524 \\
(0.535)\end{array}$ & 1 & non & $\begin{array}{c}-2.882 \\
(0.00061)\end{array}$ & 1 \\
\hline Y3 & Constant & $\begin{array}{c}-2.2786 \\
(0.1885)\end{array}$ & 2 & non & $\begin{array}{c}-2.556 \\
(0.0141)\end{array}$ & 2 \\
\hline $\mathbf{X 1}$ & Constant & $\begin{array}{c}-0.83749 \\
(0.785)\end{array}$ & 1 & non & $\begin{array}{c}-2.351 \\
(0.0236)\end{array}$ & 1 \\
\hline $\mathbf{X 2}$ & Constant & $\begin{array}{c}-2.111 \\
(0.2425)\end{array}$ & 2 & Constant & $\begin{array}{c}-3.606 \\
(0.0174)\end{array}$ & 2 \\
\hline $\mathbf{X 3}$ & Constant & $\begin{array}{c}-1.356 \\
(0.5807)\end{array}$ & 1 & Constant & $\begin{array}{c}-2.679 \\
(0.0105)\end{array}$ & 1 \\
\hline
\end{tabular}

Source: From the work of the researcher depending on the results of the program EVIEWS.10

Note from the previous table that all variables are settled in the first difference and the ARDL model can be applied.

\section{The first model: The general level of stock prices}

\section{- Determination of optimal deceleration periods}

Examining the optimal delay periods for differences: We will conduct them through the Akaike Information Standard (1973): it was found that the optimal delay periods according to this criterion for the first model are: $(1,1,3,1)$.

Akaike Information Criteria (top 20 models)

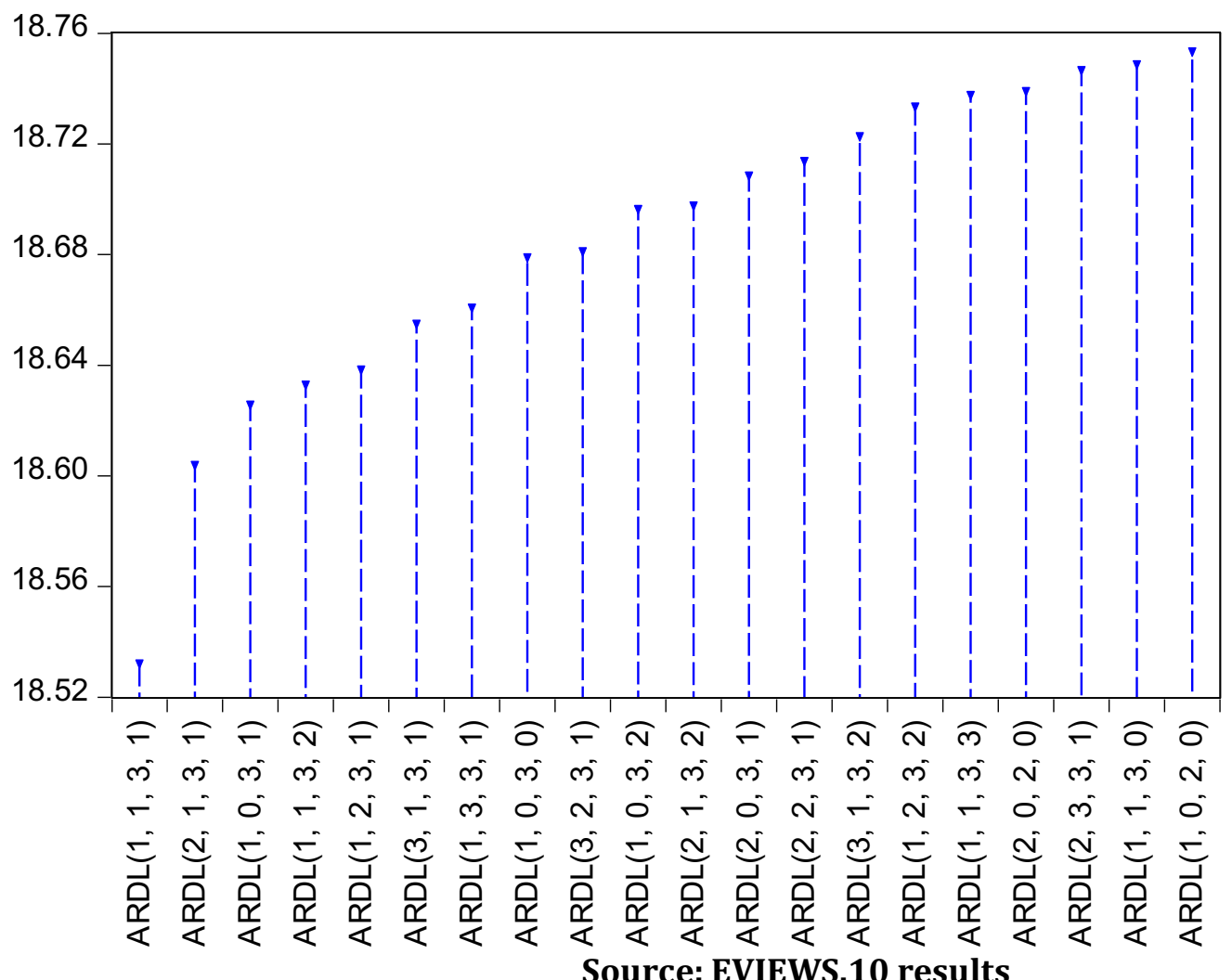




\section{Bounds Testing Approach}

Table (2): Bounds Testing Approach

\begin{tabular}{|c|c|c|}
\hline Test Statistic & Value & $\mathrm{k}$ \\
\hline F-statistic & 6.463978 & 3 \\
\hline $\begin{array}{c}\text { Critical Value } \\
\text { Bounds }\end{array}$ & & \\
\hline Significance & I0 Bound & I1 Bound \\
\hline $10 \%$ & 2.72 & 3.77 \\
\hline $5 \%$ & 3.23 & 4.35 \\
\hline $2.50 \%$ & 3.69 & 4.89 \\
\hline $1 \%$ & 4.29 & 5.61 \\
\hline
\end{tabular}

Source: EVIEWS.10 results

The above table shows the results of the combined integration test using the Bounds Test. The results indicate that the calculated value of F-statistic is greater than the minimum critical values at most levels of morale, and we reject the null hypothesis that there is no common integration relationship between the variable This means that there is a long-term balance between the general price level of stocks and macroeconomic variables.

\section{Estimation error correction model (ECM)}

After confirming a long-term equilibrium relationship we now estimate the short and long effects Term as shown in the following table:

Table (3): ARDL Cointegrating And Long Run Form

\begin{tabular}{ccccc}
\hline \hline \multicolumn{5}{c}{ Cointegrating Form } \\
\hline \hline Variable & Coefficient & Std. Error & t-Statistic & Prob. \\
\hline \hline $\mathrm{D}(\mathrm{X} 1)$ & -0.001928 & 0.003269 & -0.589710 & 0.5717 \\
$\mathrm{D}(\mathrm{X} 2)$ & 800.640837 & 980.010014 & 0.816972 & 0.4376 \\
$\mathrm{D}(\mathrm{X} 2(-1))$ & 573.969446 & 1404.207673 & 0.408750 & 0.6934 \\
$\mathrm{D}(\mathrm{X} 2(-2))$ & 2306.535804 & 1047.446229 & 2.202057 & 0.0588 \\
$\mathrm{D}(\mathrm{X} 3)$ & 200.648062 & 490.450238 & 0.409110 & 0.6932 \\
CointEq(-1) & -1.429295 & 0.331347 & -4.313595 & 0.0026 \\
\hline \hline Cointeq = Y1 - (-0.0046*X1 -1875.4657*X2+626.4976*X3+20081.8986) \\
\hline \hline \multicolumn{5}{c}{ Long Run Coefficients } \\
\hline \hline Variable & Coefficient & Std. Error & t-Statistic & Prob. \\
\hline \hline X1 & -0.004641 & 0.001568 & -2.960493 & 0.0181 \\
X2 & -1875.465694 & 713.374358 & -2.629006 & 0.0302 \\
X3 & 626.497618 & 207.420923 & 3.020417 & 0.0165 \\
C & 20081.898641 & 4855.396105 & 4.135996 & 0.0033 \\
\hline \hline
\end{tabular}

Source: EVIEWS.10 results

The table is composed of two parts, where the upper part illustrates the estimation of the error correction model and the relationship Short term while the bottom shows the estimation of the long-term relationship. 
Short term relationship: The error correction model shows that all variables are not statistically significant at.

A significant 5\%, which means the weak effect of the explanatory variables (macroeconomic variables) on the general level of stock prices in the short term.

The results of the error correction model showed that the coefficient of slowing the error correction limit reveals. The speed (or slowness) of changing the change to the state of equilibrium, and this factor must be significant, The signal indicates the existence of a common integration between the variables and indicates the absolute value, For the error correction limit parameter to the speed of restoring the balance state, the negative sign shows affinity, Short-term kinetic model, and negative and moral factors associated with slowing down, Correcting the error is a more effective way of showing the common integration. In this model, the value of the error correction coefficient (CointEq(-1)), which means the speed of error correction, negative, is about 1.42 , ie $142 \%$, and we note that it is of strong statistical significance, which increases the accuracy and validity of the balance in the long term, Balance mode can be back less than six months.

Long Term Relationship: The above results indicate the negative impact of GDP on the stock market index. This effect is contrary to the axiomatic point of view, but can be interpreted as associated with the growth of the economy or the decline in growth with stock market policies such as keeping a portion of profits for new investments and other actions.

The negative impact of the variable interest rate and this is consistent with economic theory, that the more the rate of interest on deposits people tend to deposit their savings in banks and not to invest in the stock market and vice versa.

The positive effect of the variable inflation rate and also this effect is consistent with economic theory.

We note that the constant is significant, and the variables are all significant in the long term effect.

\section{Test results for the stability of the variation of error limits (homogeneity of variance)}

Several tests have been conducted to detect that the variance of homogeneity is homogeneous or not, including the ARCH test. This test is based on a lager multiplier LM.

Note from the table that the variation of error limits is not homogeneous. 
Table (4): Heteroskedasticity Test: ARCH.

\begin{tabular}{|c|c|c|c|c|}
\hline $\begin{array}{l}\text { F-statistic } \\
\text { Obs*R-squared }\end{array}$ & $\begin{array}{l}0.148797 \\
0.166980\end{array}$ & \multicolumn{2}{|c|}{$\begin{array}{l}\text { Prob. } F(1,15) \\
\text { Prob. Chi-Square(1) }\end{array}$} & $\begin{array}{l}0.7051 \\
0.6828\end{array}$ \\
\hline \multicolumn{5}{|c|}{$\begin{array}{l}\text { Test Equation: } \\
\text { Dependent Variable: RESID^2 } \\
\text { Method: Least Squares }\end{array}$} \\
\hline Variable & Coefficient & Std. Error & t-Statistic & Prob. \\
\hline $\begin{array}{c}C \\
\operatorname{RESID}^{\wedge} 2(-1)\end{array}$ & $\begin{array}{l}2029559 . \\
0.099188\end{array}$ & $\begin{array}{l}1133829 . \\
0.257135\end{array}$ & $\begin{array}{l}1.790005 \\
0.385742\end{array}$ & $\begin{array}{l}0.0937 \\
0.7051\end{array}$ \\
\hline $\begin{array}{l}\text { R-squared } \\
\text { Adjusted R-squared } \\
\text { S.E. of regression } \\
\text { Sum squared resid } \\
\text { Log likelihood } \\
\text { F-statistic } \\
\text { Prob(F-statistic) }\end{array}$ & $\begin{array}{r}0.009822 \\
-0.056190 \\
4014177 \\
2.42 \mathrm{E}+14 \\
-281.5489 \\
0.148797 \\
0.705104\end{array}$ & \multicolumn{2}{|c|}{$\begin{array}{l}\text { Mean dependent var } \\
\text { S.D. dependent var } \\
\text { Akaike info criterion } \\
\text { Schwarz criterion } \\
\text { Hannan-Quinn criter. } \\
\text { Durbin-Watson stat }\end{array}$} & $\begin{array}{l}2253724 . \\
3905940 . \\
33.35869 \\
33.45672 \\
33.36844 \\
1.936550\end{array}$ \\
\hline
\end{tabular}

\section{Source: EVIEWS.10 results}

\section{Test the stability of the model}

In order to ensure that the data used in this study are free of structural changes

You must use one of the appropriate tests for this, such as: Cumulative total of the repeated condom (CUSUM).

The following diagram shows that the cumulative sum of the CUSUM for this model is a median line within the boundaries of the critical area, indicating the stability of the model at a significant limit of $5 \%$.

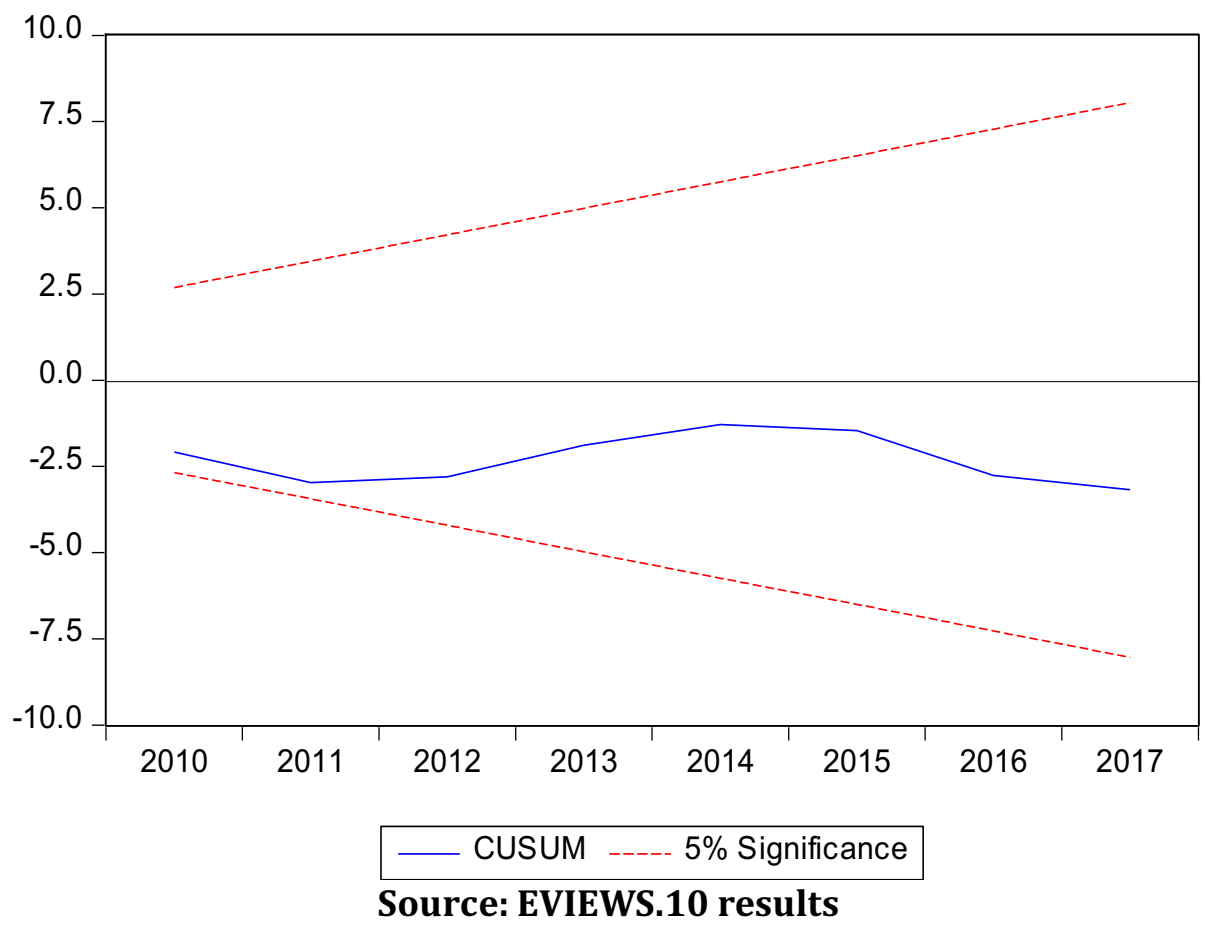




\section{Results of normal distribution test for condoms}

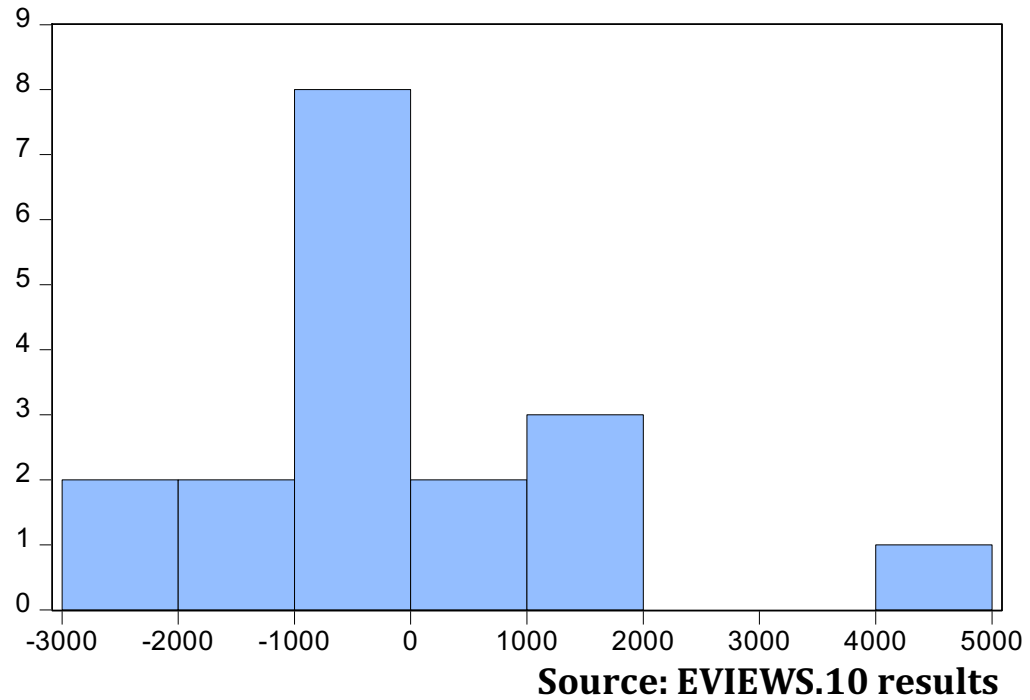

Series: Residuals

Sample 20002017

Observations 18

$\begin{array}{lc}\text { Mean } & 3.28 \mathrm{e}-12 \\ \text { Median } & -288.4551 \\ \text { Maximum } & 4009.552 \\ \text { Minimum } & -2343.337 \\ \text { Std. Dev. } & 1510.453 \\ \text { Skewness } & 0.858923 \\ \text { Kurtosis } & 3.956794 \\ & \\ \text { Jarque-Bera } & 2.899838 \\ \text { Probability } & 0.234589\end{array}$

We note from the previous figure that the residues are subject to normal distribution.

\section{Predictive performance test}

We observe through diagnostic tests that the model has a high predictive ability as shown in the following figure

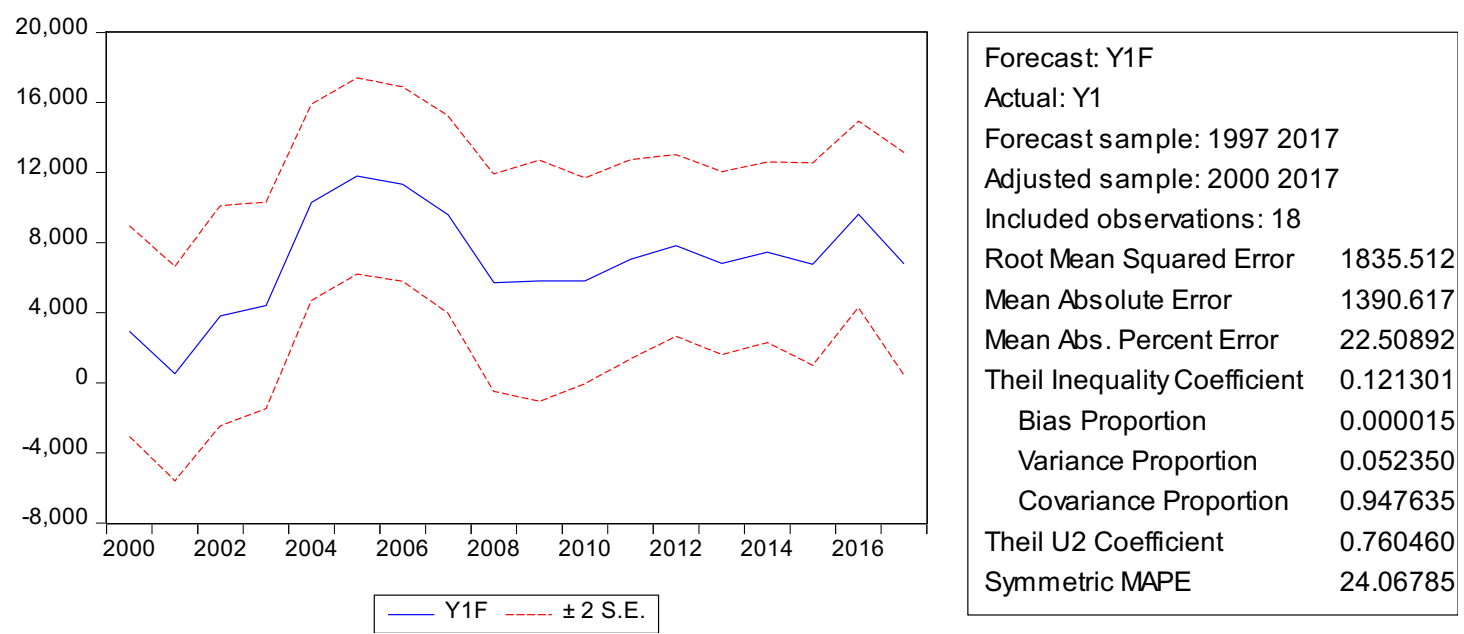

Source: EVIEWS.10 results 


\section{The second model: Market Value of Shares}

\section{- Determination of optimal deceleration periods}

Akaike Information Criteria (top 20 models)

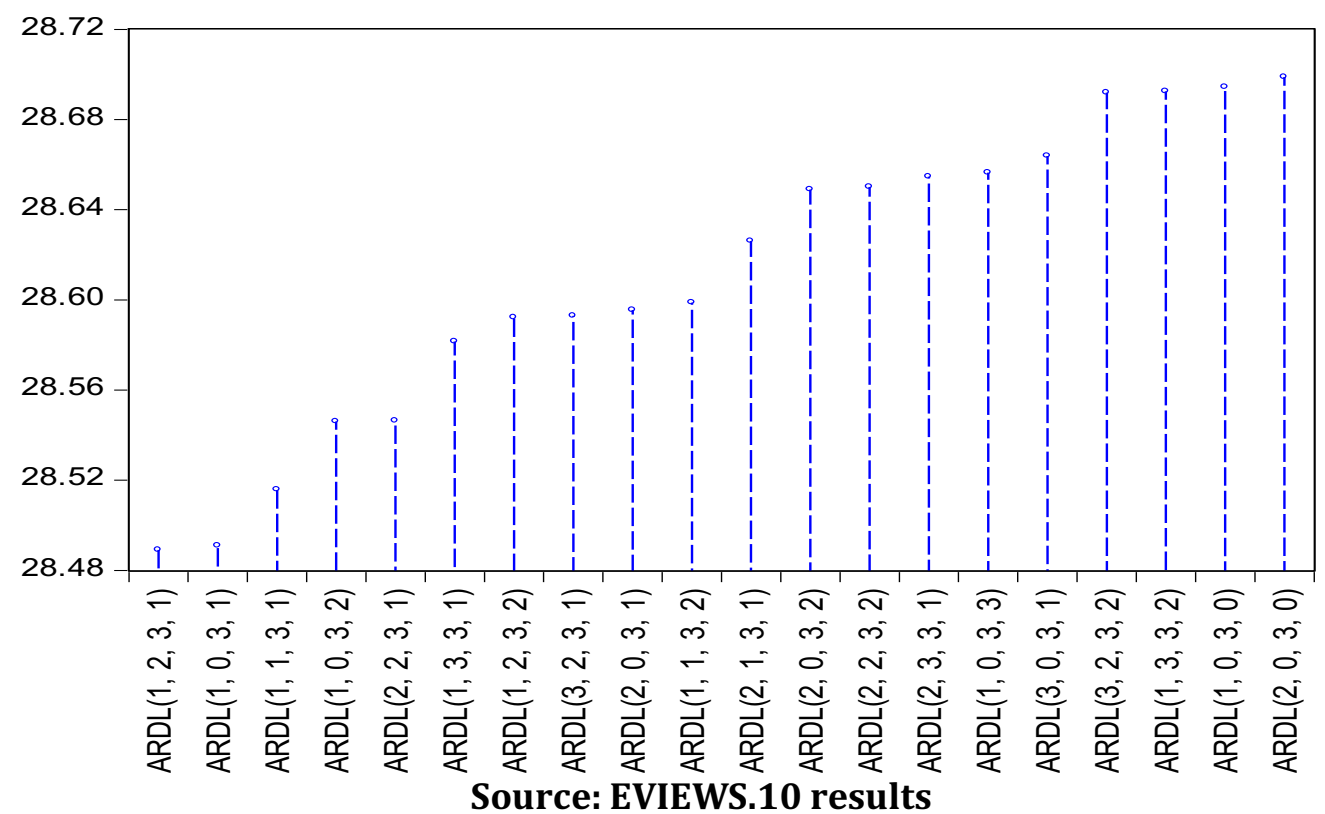

Examining the optimal delay periods for differences: We will conduct them through the Akaike Information Standard (1973): it was found that the optimal delay periods according to this criterion for the first model are: $(1,2,3,1)$.

\section{Bounds Testing Approach}

Table (5): Bounds Testing Approach

\begin{tabular}{lcc}
\hline \hline Test Statistic & Value & $\mathrm{k}$ \\
\hline \hline F-statistic & 7.773968 & 3 \\
\hline \hline
\end{tabular}

Critical Value Bounds

\begin{tabular}{lcc}
\hline \hline Significance & I0 Bound & I1 Bound \\
\hline \hline $10 \%$ & 2.72 & 3.77 \\
$5 \%$ & 3.23 & 4.35 \\
$2.5 \%$ & 3.69 & 4.89 \\
$1 \%$ & 4.29 & 5.61 \\
\hline \hline
\end{tabular}

Source: EVIEWS.10 results

The above table shows the results of the combined integration test using the Bounds Test. The results indicate that the calculated value of F-statistic is greater than the minimum critical values at most levels of morale, and we reject the null hypothesis that there is no common integration relationship between the variable This means that there is a long-term balance between the general price level of stocks and macroeconomic variables.

\section{Estimation error correction model (ECM)}

After confirming a long-term equilibrium relationship we now estimate the short and long effects Term as shown in the following table: 
Table (6): ARDL Cointegrating And Long Run Form

\begin{tabular}{ccccc}
\hline \hline \multicolumn{6}{c}{ Cointegrating Form } & \\
\hline \hline Variable & Coefficient & Std. Error & t-Statistic & Prob. \\
\hline \hline $\mathrm{D}(\mathrm{X} 1)$ & -0.041206 & 0.472533 & -0.087203 & 0.9330 \\
$\mathrm{D}(\mathrm{X} 1(-1))$ & -0.437243 & 0.429854 & -1.017189 & 0.3429 \\
$\mathrm{D}(\mathrm{X} 2)$ & 115517.276476 & 144318.617608 & 0.800432 & 0.4498 \\
$\mathrm{D}(\mathrm{X} 2(-1))$ & 102119.574102 & 218524.694801 & 0.467314 & 0.6545 \\
$\mathrm{D}(\mathrm{X} 2(-2))$ & 370768.890998 & 153996.169762 & 2.407650 & 0.0469 \\
$\mathrm{D}(\mathrm{X})$ & 22140.479606 & 70563.056965 & 0.313769 & 0.7628 \\
CointEq(-1) & -1.522244 & 0.321390 & -4.736435 & 0.0021 \\
\hline \hline Cointeq $=\mathrm{Y} 2-(-0.3411 * \mathrm{X} 1$ & $-253667.4007 * \mathrm{X} 2+99038.6940 * \mathrm{X} 3+$ & \\
2552260.5415 $)$ & & & \\
\hline \hline
\end{tabular}

Long Run Coefficients

\begin{tabular}{ccccc}
\hline \hline Variable & Coefficient & Std. Error & t-Statistic & Prob. \\
\hline \hline X1 & -0.341104 & 0.217838 & -1.565858 & 0.1614 \\
X2 & -253667.400714 & 98967.274120 & -2.563144 & 0.0374 \\
X3 & 99038.694037 & 29767.676995 & 3.327055 & 0.0126 \\
C & 2552260.541536 & 675915.547279 & 3.776005 & 0.0069 \\
\hline \hline
\end{tabular}

Source: EVIEWS.10 results

The table is composed of Two parts, where the upper part illustrates the estimation of the error correction model and the relationship Short term while the bottom shows the estimation of the long-term relationship.

Short term relationship: The error correction model shows that all variables are not statistically significant at.

A significant 5\%, which means the weak effect of the explanatory variables (macroeconomic variables) on the general level of stock prices in the short term.

The results of the error correction model showed that the coefficient of slowing the error correction limit reveals. The speed (or slowness) of changing the change to the state of equilibrium, and this factor must be significant, The signal indicates the existence of a common integration between the variables and indicates the absolute value, For the error correction limit parameter to the speed of restoring the balance state, the negative sign shows affinity, Short-term kinetic model, and negative and moral factors associated with slowing down, Correcting the error is a more effective way of showing the common integration. In this model, the value of the error correction coefficient (CointEq(-1)), which means the speed of error correction, negative, is about 1.52, (152\%), and we note that it is of strong statistical significance, which increases the accuracy and validity of the balance in the long term, Balance mode can be back less than six months.

Long Term Relationship: The above results indicate the negative impact of GDP on the stock market index. This effect is contrary to the axiomatic point of view, but can be interpreted as associated with the growth of the economy or the decline in growth with stock market policies such as keeping a portion of profits for new investments and other actions. 
The negative impact of the variable interest rate and this is consistent with economic theory, that the more the rate of interest on deposits people tend to deposit their savings in banks and not to invest in the stock market and vice versa.

The positive effect of the variable inflation rate and also this effect is consistent with economic theory.

We note that the constant is significant, and the variables are all significant in the long term effect.

Test results for the stability of the variation of error limits (homogeneity of variance) Several tests have been conducted to detect that the variance of homogeneity is homogeneous or not, including the ARCH test. This test is based on a lager multiplier LM.

Note from the table that the variation of error limits is not homogeneous.

Table (7): Heteroskedasticity Test: ARCH.

\begin{tabular}{lrllc}
\hline \hline F-statistic & 0.440169 & Prob. F(1,15) & 0.5171 \\
Obs*R-squared & 0.484636 & Prob. Chi-Square(1) & 0.4863 \\
\hline \hline \multicolumn{1}{c}{ Variable } & Coefficient & Std. Error & t-Statistic & Prob. \\
\hline \hline \multicolumn{1}{c}{ C } & $3.52 \mathrm{E}+10$ & $2.15 \mathrm{E}+10$ & 1.637343 & 0.1224 \\
\multicolumn{1}{c}{ RESID $^{\wedge}$ 2(-1) } & 0.169542 & 0.255545 & 0.663452 & 0.5171 \\
\hline \hline R-squared & 0.028508 & Mean dependent var & $4.25 \mathrm{E}+10$ \\
Adjusted R-squared & -0.036258 & S.D. dependent var & $7.48 \mathrm{E}+10$ \\
S.E. of regression & $7.61 \mathrm{E}+10$ & Akaike info criterion & 53.05947 \\
Sum squared resid & $8.69 \mathrm{E}+22$ & Schwarz criterion & 53.15750 \\
Log likelihood & -449.0055 & Hannan-Quinn criter. & 53.06921 \\
F-statistic & 0.440169 & Durbin-Watson stat & 1.896170 \\
Prob(F-statistic) & 0.517109 & & & \\
\hline \hline
\end{tabular}

Source: EVIEWS.10 results

\section{Test the stability of the model}

In order to ensure that the data used in this study are free of structural changes

You must use one of the appropriate tests for this, such as: Cumulative total of the repeated condom (CUSUM).

The following diagram shows that the cumulative sum of the CUSUM for this model is a median line within the boundaries of the critical area, indicating the stability of the model at a significant limit of $5 \%$. 


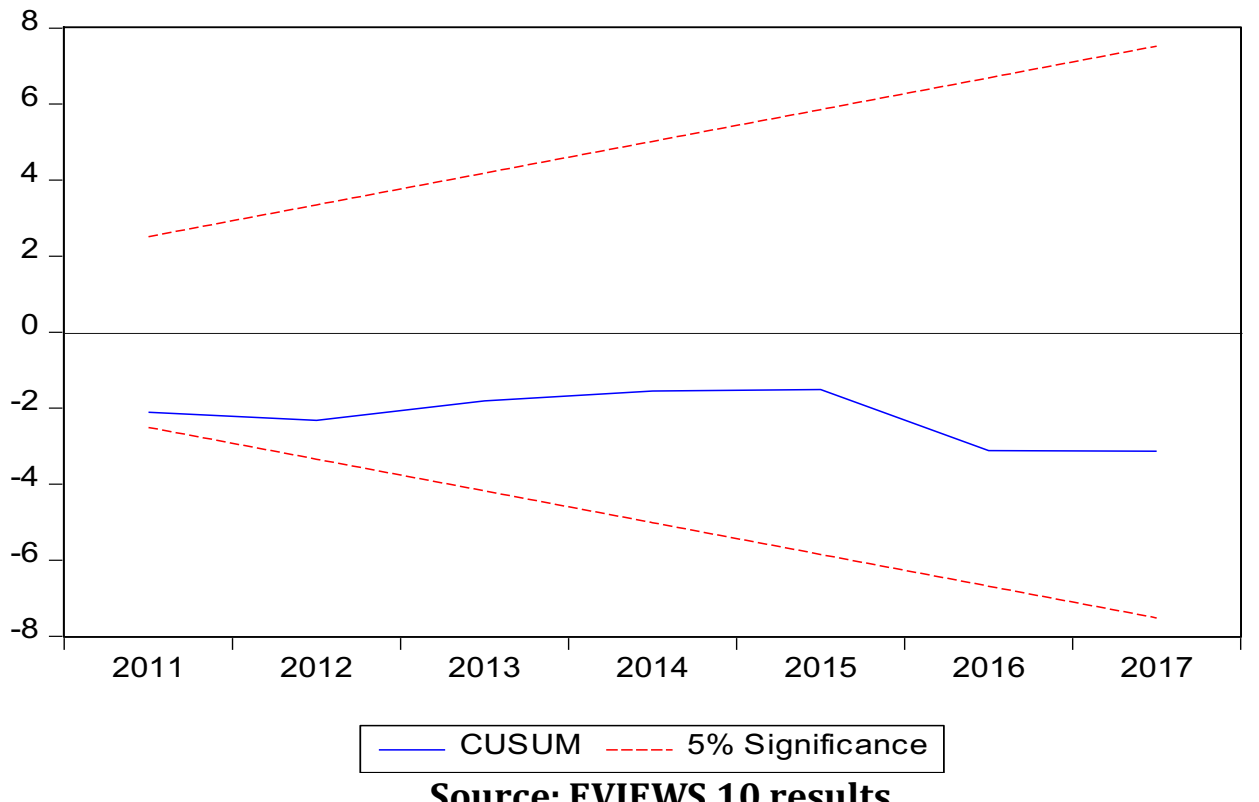

Source: EVIEWS.10 results

\section{Results of normal distribution test for condoms}

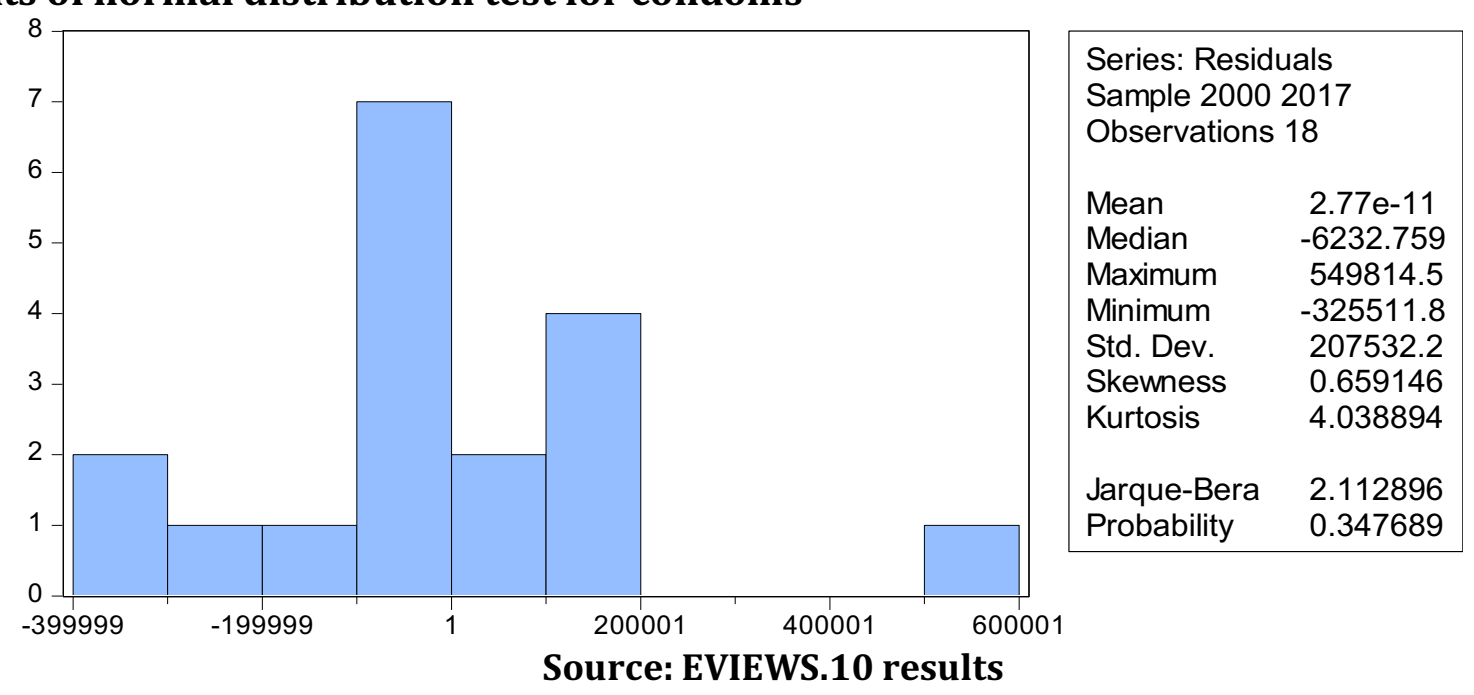

We note from the previous figure that the residues are subject to normal distribution.

\section{Predictive performance test}

We observe through diagnostic tests that the model has a high predictive ability as shown in the following figure

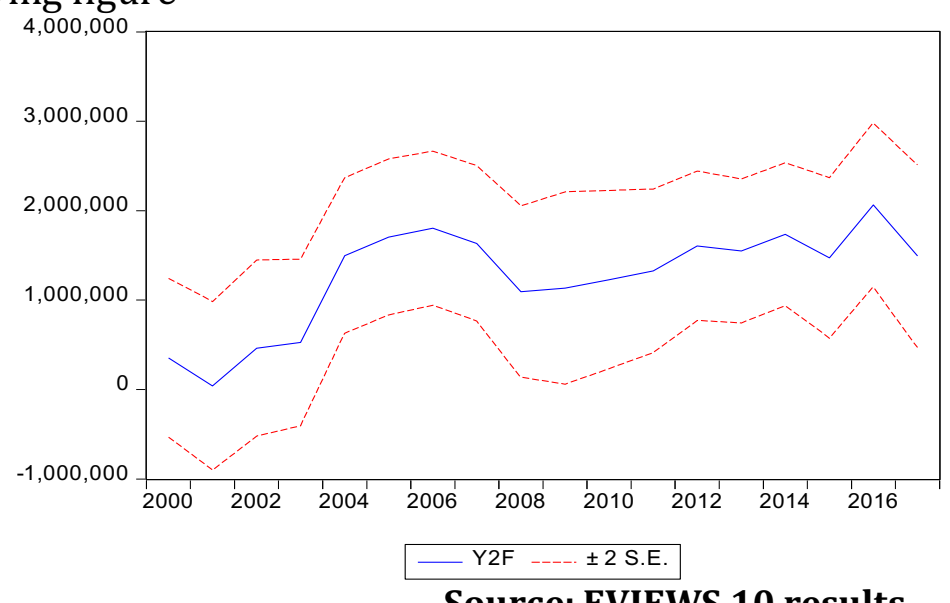

\begin{tabular}{|c|c|}
\hline \multicolumn{2}{|l|}{ Forecast: Y2F } \\
\hline \multicolumn{2}{|l|}{ Actual: Y2 } \\
\hline \multicolumn{2}{|l|}{ Forecast sample: 19972017} \\
\hline \multicolumn{2}{|l|}{ Adjusted sample: 20002017} \\
\hline \multicolumn{2}{|l|}{ Included observations: 18} \\
\hline Root Mean Squared Error & 291045.0 \\
\hline Mean Absolute Error & 228468.5 \\
\hline Mean Abs. Percent Error & 23.92529 \\
\hline Theil Inequality Coefficient & 0.104841 \\
\hline Bias Proportion & 0.000166 \\
\hline Variance Proportion & 0.028668 \\
\hline Covariance Proportion & 0.971166 \\
\hline Theil U2 Coefficient & 0.730186 \\
\hline Symmetric MAPE & 25.77409 \\
\hline
\end{tabular}

Source: EVIEWS.10 results 


\section{The third model: Value of Shares Traded}

\section{- Determination of optimal deceleration periods}

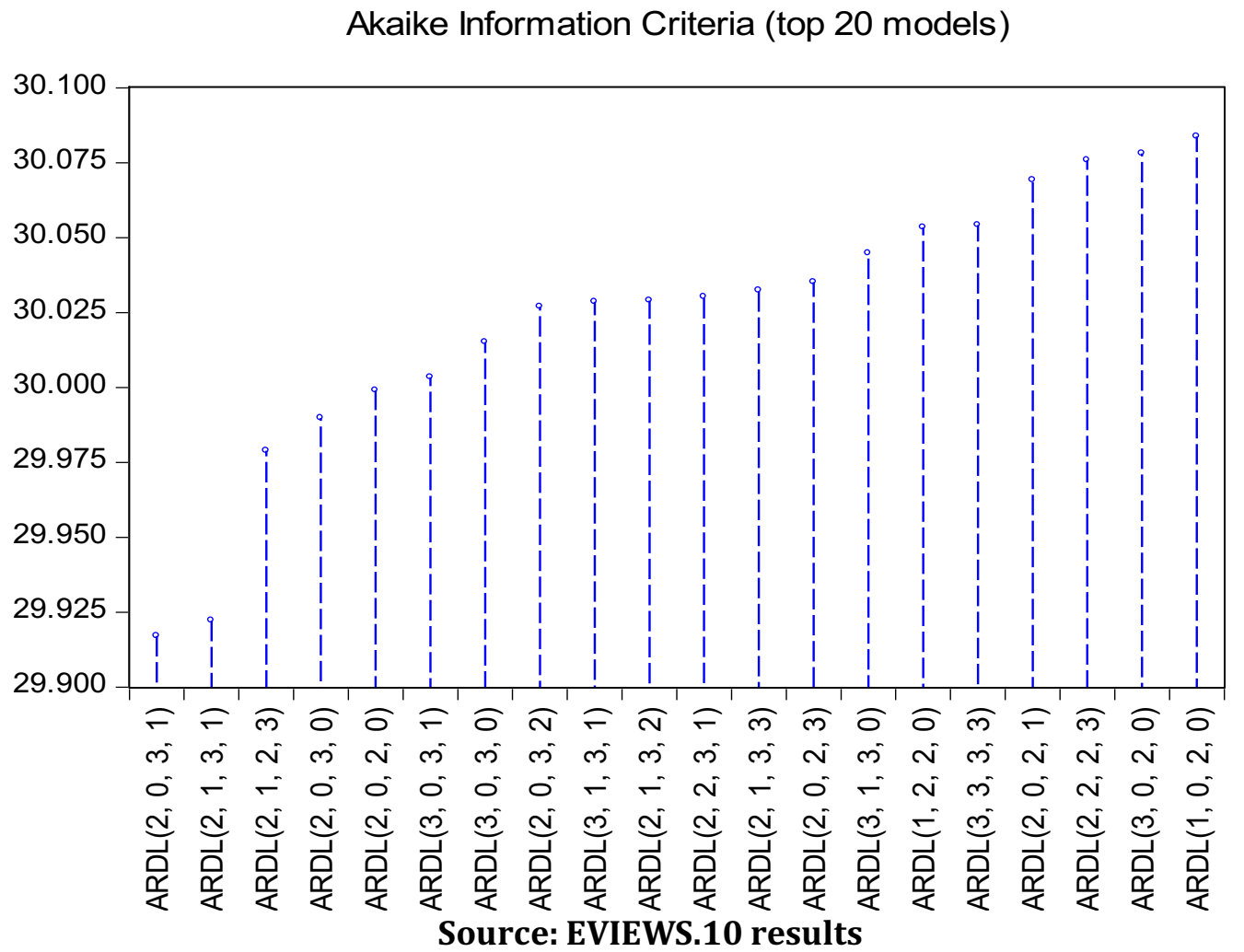

Examining the optimal delay periods for differences: We will conduct them through the Akaike Information Standard (1973): it was found that the optimal delay periods according to this criterion for the first model are: $(2,0,3,1)$.

\section{Bounds Testing Approach}

Table (8): Bounds Testing Approach

\begin{tabular}{lcc}
\hline \hline Test Statistic & Value & $\mathrm{k}$ \\
\hline \hline F-statistic & 3.450067 & 3 \\
\hline \hline Critical Value Bounds & & \\
\hline \hline Significance & I0 Bound & I1 Bound \\
\hline \hline $10 \%$ & 2.72 & 3.77 \\
$5 \%$ & 3.23 & 4.35 \\
$2.5 \%$ & 3.69 & 4.89 \\
$1 \%$ & 4.29 & 5.61 \\
\hline \hline
\end{tabular}

Source: EVIEWS.10 results

The above table shows the results of the combined integration test using the Bounds Test. The results indicate that the calculated value of F-statistic is greater than the minimum critical values at most levels of morale, and we reject the null hypothesis that there is no common integration relationship between the variable This means that there is a long-term balance between the general price level of stocks and macroeconomic variables. 


\section{Estimation error correction model (ECM)}

After confirming a long-term equilibrium relationship we now estimate the short and long effects Term as shown in the following table:

Table (9): ARDL Cointegrating And Long Run Form

\begin{tabular}{ccccc}
\hline \hline \multicolumn{5}{c}{ Cointegrating Form } \\
\hline \hline Variable & Coefficient & Std. Error & t-Statistic & Prob. \\
\hline \hline $\mathrm{D}(\mathrm{Y3}(-1))$ & 0.673998 & 0.334081 & 2.017467 & 0.0784 \\
$\mathrm{D}(\mathrm{X} 1)$ & -2.084387 & 0.752819 & -2.768775 & 0.0243 \\
$\mathrm{D}(\mathrm{X} 2)$ & 390645.834303 & 253092.884829 & 1.543488 & 0.1613 \\
$\mathrm{D}(\mathrm{X} 2(-1))$ & 666264.806173 & 332867.354582 & 2.001593 & 0.0803 \\
$\mathrm{D}(\mathrm{X} 2(-2))$ & 568081.118846 & 365972.616313 & 1.552250 & 0.1592 \\
$\mathrm{D}(\mathrm{X})$ & 480024.190850 & 169233.374768 & 2.836463 & 0.0219 \\
CointEq(-1) & -1.655509 & 0.453286 & -3.652241 & 0.0065 \\
\hline \hline
\end{tabular}

Long Run Coefficients

\begin{tabular}{ccccc}
\hline \hline Variable & Coefficient & Std. Error & t-Statistic & Prob. \\
\hline \hline X1 & -1.259061 & 0.403163 & -3.122956 & 0.0142 \\
X2 & -321547.407415 & 168176.479602 & -1.911964 & 0.0923 \\
X3 & 380664.871554 & 52149.390686 & 7.299508 & 0.0001 \\
C & 4242318.209497 & 1231508.104331 & 3.444816 & 0.0088 \\
\hline \hline
\end{tabular}

\section{Source: EVIEWS.10 results}

The table is composed of two parts, where the upper part illustrates the estimation of the error correction model and the relationship Short term while the bottom shows the estimation of the long-term relationship.

Short term relationship: The error correction model shows that all variables are not statistically significant at.

A significant 5\%, which means the weak effect of the explanatory variables macroeconomic variables) on the general level of stock prices in the short term.

The results of the error correction model showed that the coefficient of slowing the error correction limit reveals. The speed (or slowness) of changing the change to the state of equilibrium, and this factor must be significant, The signal indicates the existence of a common integration between the variables and indicates the absolute value, For the error correction limit parameter to the speed of restoring the balance state, the negative sign shows affinity, Short-term kinetic model, and negative and moral factors associated with slowing down, Correcting the error is a more effective way of showing the common integration. In this model, the value of the error correction coefficient (CointEq(-1)), which means the speed of error correction, negative, is about 1.65, (165\%), and we note that it is of strong statistical significance, which increases the accuracy and validity of the balance in the long term, Balance mode can be back less than six months. 
Long Term Relationship:The above results indicate the negative impact of GDP on the stock market index. This effect is contrary to the axiomatic point of view, but can be interpreted as associated with the growth of the economy or the decline in growth with stock market policies such as keeping a portion of profits for new investments and other actions.

The negative impact of the variable interest rate and this is consistent with economic theory, that the more the rate of interest on deposits people tend to deposit their savings in banks and not to invest in the stock market and vice versa.

The positive effect of the variable inflation rate and also this effect is consistent with economic theory.

We note that the constant is significant, and the variables are all significant in the long term effect.

\section{Test results for the stability of the variation of error limits (homogeneity of variance)}

Several tests have been conducted to detect that the variance of homogeneity is homogeneous or not, including the ARCH test. This test is based on a lager multiplier LM.

Note from the table that the variation of error limits is not homogeneous.

Table (10): Heteroskedasticity Test: ARCH.

\begin{tabular}{|c|c|c|c|c|}
\hline $\begin{array}{l}\text { F-statistic } \\
\text { Obs*R-squared }\end{array}$ & $\begin{array}{l}0.226905 \\
0.253327\end{array}$ & $\begin{array}{l}\text { Prob. } F(1,15) \\
\text { Prob. Chi-Square(1) }\end{array}$ & & $\begin{array}{l}0.6407 \\
0.6147\end{array}$ \\
\hline Variable & Coefficient & Std. Error & t-Statistic & Prob. \\
\hline $\mathrm{C}$ & $1.70 \mathrm{E}+11$ & $8.70 \mathrm{E}+10$ & 1.948278 & 0.0703 \\
\hline $\operatorname{RESID}^{\wedge} 2(-1)$ & 0.123303 & 0.258852 & 0.476346 & 0.6407 \\
\hline R-squared & 0.014902 & Mean dependent var & & $1.94 \mathrm{E}+11$ \\
\hline Adjusted R-squared & -0.050772 & S.D. dependent var & & $2.82 \mathrm{E}+11$ \\
\hline S.E. of regression & $2.89 \mathrm{E}+11$ & Akaike info criterion & & 55.72460 \\
\hline Sum squared resid & $1.25 \mathrm{E}+24$ & Schwarz criterion & & 55.82263 \\
\hline Log likelihood & -471.6591 & Hannan-Quinn criter. & & 55.73435 \\
\hline F-statistic & 0.226905 & Durbin-Watson stat & & 1.974384 \\
\hline Prob(F-statistic) & 0.640692 & & & \\
\hline
\end{tabular}

\section{Source: EVIEWS.10 results}

\section{Test the stability of the model}

In order to ensure that the data used in this study are free of structural changes

You must use one of the appropriate tests for this, such as: Cumulative total of the repeated condom (CUSUM).

The following diagram shows that the cumulative sum of the CUSUM for this model is a median line within the boundaries of the critical area, indicating the stability of the model at a significant limit of $5 \%$. 


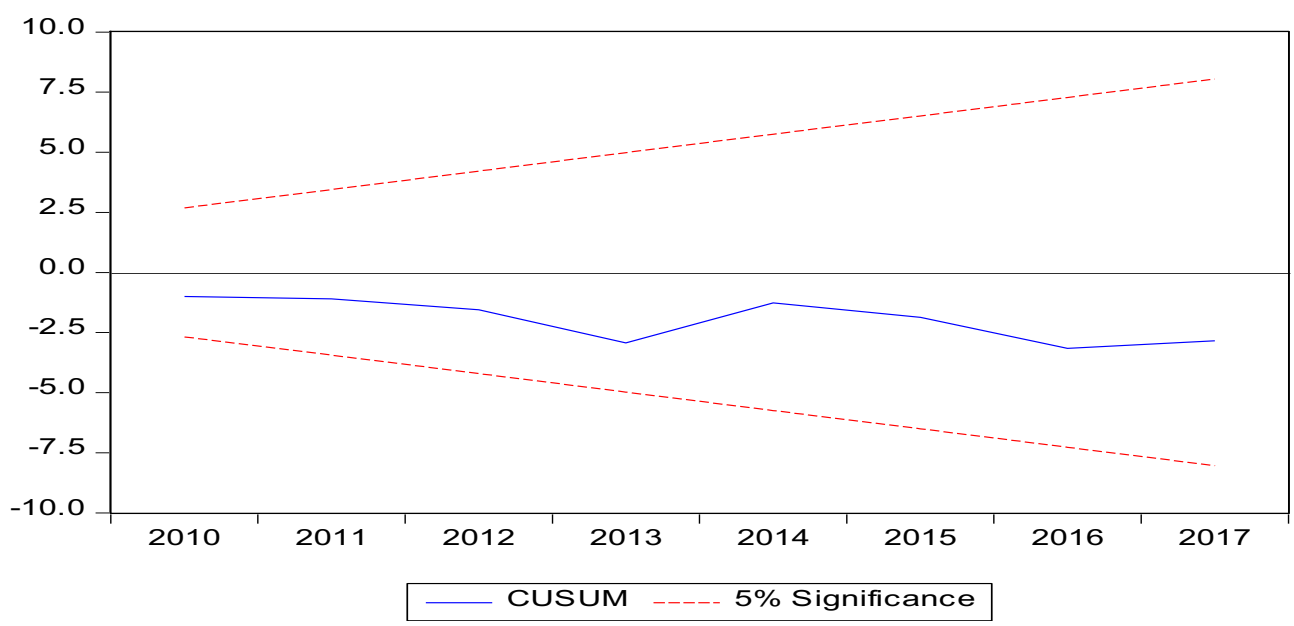

Source: EVIEWS.10 results

\section{Results of normal distribution test for condoms}

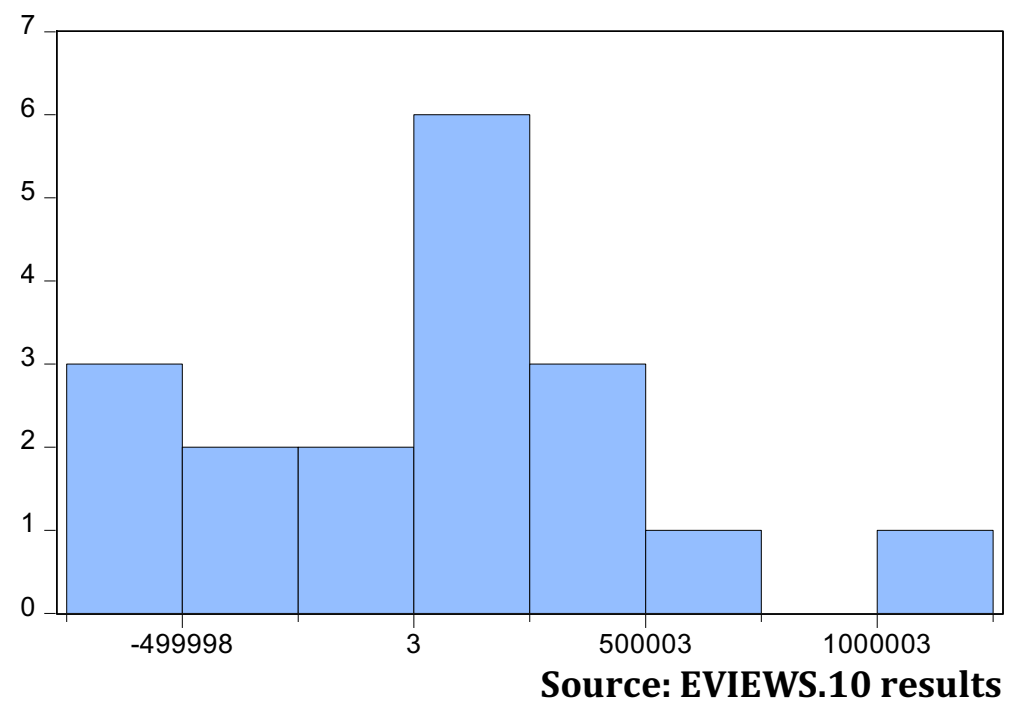

Series: Residuals

Sample 20002017

Observations 18

Mean $\quad-1.49 \mathrm{e}-09$

Median $\quad 17145.86$

Maximum 1027240.

Minimum $\quad-746652.5$

Std. Dev. $\quad 448024.5$

Skewness $\quad 0.318971$

Kurtosis $\quad 2.970476$

Jarque-Bera $\quad 0.305880$

Probability $\quad 0.858181$

We note from the previous figure that the residues are subject to normal distribution.

\section{Predictive performance test}

We observe through diagnostic tests that the model has a high predictive ability as shown in the following figure

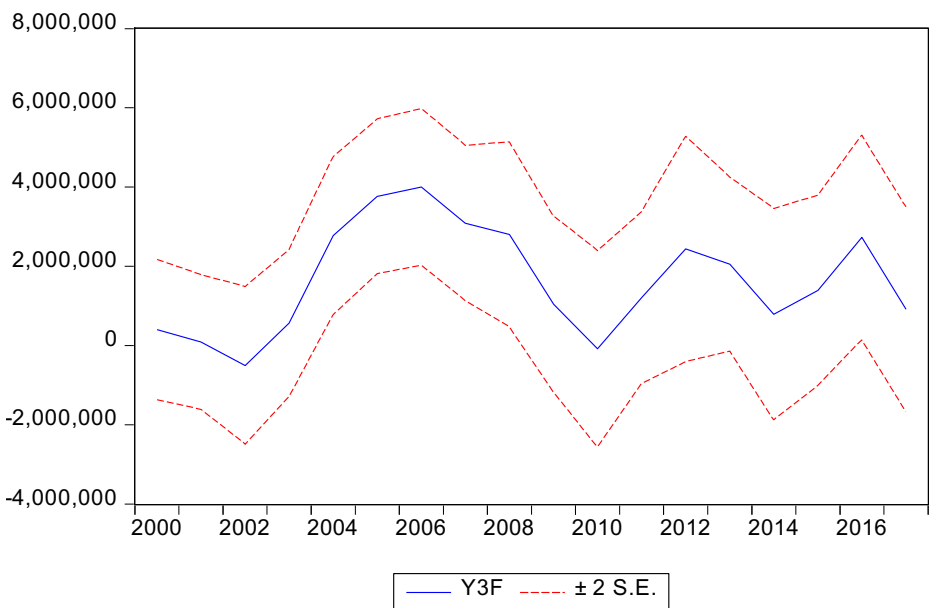

\begin{tabular}{|c|c|}
\hline \multicolumn{2}{|l|}{ Forecast: Y3F } \\
\hline \multicolumn{2}{|l|}{ Actual: Y3 } \\
\hline \multicolumn{2}{|l|}{ Forecast sample: 19972017} \\
\hline \multicolumn{2}{|l|}{ Adjusted sample: 20002017} \\
\hline \multicolumn{2}{|l|}{ Included observations: 18} \\
\hline Root Mean Squared Error & 749468.7 \\
\hline Mean Absolute Error & 591503.0 \\
\hline Mean Abs. Percent Error & 88.30430 \\
\hline Theil Inequality Coefficient & 0.179620 \\
\hline Bias Proportion & 0.002474 \\
\hline Variance Proportion & 0.000061 \\
\hline Covariance Proportion & 0.997465 \\
\hline Theil U2 Coefficient & 1.782530 \\
\hline Symmetric MAPE & 54.42734 \\
\hline
\end{tabular}

Source: EVIEWS.10 results 


\section{SUMMARY}

The motivation behind this research is the measurement of relationship between macroeconomic variables measured (GDP, interest rate, inflation rate) in the financial market performance indicators (stock price index, Market Value of Shares, Value of Shares Traded) Using the ARDL model to estimate the relationship between Saudi macro-economic variables and Saudi stock market performance indicators.

Data were collected using a site related to Saudi Arabia. Data was measured using EVIEWS.10. The data collected and discussed were analyzed to test the impact of macroeconomic variables on the performance indicators of the financial market. The results showed that the effect of macroeconomic variables on performance indicators in the Saudi stock market is not important in the short term and that there is a significant long-term effect according to the proposed models.

\section{CONCLUSION}

- The existence of a long-term integrative relationship between the indicators of the Saudi stock market and macroeconomic variables and this relationship is significant.

- There is an inverse relationship between Saudi Arabia's long-term stock market indices, GDP variables, and deposit interest rates.

- There is a positive correlation between the indices of the Saudi stock market in the long term and the variable inflation rate.

\section{RECOMMENDATIONS}

- The need to control macroeconomic variables by the government, especially in strategic planning, in order to create an appropriate investment climate in the Saudi stock market, which in turn will benefit the economic growth in Saudi Arabia.

- Research the causes of fluctuations that contribute to the instability of the stock market by studying the impact of other variables on the Saudi stock market.

- Encouraging investment in the stock market by taking advantage of the results of this study and other future studies by linking the general economic policy with the policy of developing the stock market in the Kingdom of Saudi Arabia.

\section{References}

Abedallat \& Al-Shabib (2012). Impact of the investment and gross domestic product on the Amman Stock Exchange index, Investment Management and Financial Innovations, Volume9, Issue 3, 130 - 136.

Acikalin \& Aktas \& Unal (2008), Relationships between stock markets and macroeconomic variables: an empirical analysis of the Istanbul Stock Exchange, Investment Management and Financial Innovations, Volume 5, Issue 1, 2008.

Aigbovo \& Izekor (2015). The Impact Of Macroeconomic Variables On Stock Market Index In Nigeria, African Journal of Management Sciences (AJMS) Vol. 1 No 1, Sept 2015.

Amata (2017), Effect Of Macroeconomic Variables On Stock Market Volatility In Kenya., Degree of Doctor of Philosophy in Business Administration, Finance in the Jomo Kenyatta University of Agriculture and Technology, $\mathrm{p}$ 195.

Aggarwal \& Saqib (2017), Impact of Macro Economic Variables of India and USA on Indian Stock Market, International Journal of Economics and Financial, 10 - 14.

AL-Shogeathri, Mofleh Ali (2011), Macroeconomic Determinants Of The Stock Market Movements: Empirical Evidence From The Saudi Stock Market, Submitted in partial fulfillment of the requirements for the degree Doctor, KANSAS STATE UNIVERSITY, p 215.

Jamaludin \& Ismail \& Ab Manaf (2017). Macroeconomic Variables and Stock Market Returns: Panel Analysis from Selected ASEAN Countries, International Journal of Economics and Financial Issues, 2017, 7(1), 37-45. 
Kalyanaraman \& Tuwajri (2014), Macroeconomic Forces and Stock Prices: Some Empirical Evidence from Saudi Arabia, International Journal of Financial Research, Vol. 5, No. 1; 81- 92.

Kumar \& Puja (2012),The impact of macroeconomic fundamentalson stock prices revisited: An evidence from Indian data, Eurasian Journal of Business and Economics 2012, 5 (10), 25-44.

Kirui \& H. W. Wawire \& O. Onono (2014), Macroeconomic Variables, Volatility and Stock Market Returns: ACase of Nairobi Securities Exchange, Kenya., International Journal of Economics and Finance; Vol. 6, No. 8;214 - 228.

Khan \& Khan (2018), The Impact of Macroeconomic Variables on Stock Prices: A Case Study of Karachi Stock Exchange, Business and Economics Journal, Volume 9 Issue 3, 1 - 8.

Muazu \& Alhassan (2014), An Econometric Analysis of the Impact of Macroeconomic Fundamentalson Stock Market Returns in Ghana, macrothink institute journals, Vol. 6, No. 2, 47- 72.

Mu'tasem \& Naomie (2016), The Impact of Macroeconomic Factors on Saudi Stock Market (Tadawul) Prices, Int'l Conf. on Advances in Big Data Analytics / ABDA'16 |, 71-76.

Ndlovu \& Faisal \& Resatoglu \&Türsoy (2018), The Impact of Macroeconomic Variables on Stock Returns: A Case of the Johannesburg Stock Exchange, Romanian Statistical Review nr. 2 / 2018, 87 - 104.

O. Owino (2014), Macroeconomic Variables And Equity Securities' Market Indices:

Case Of The Nairobi Securities Exchange, A research paper submitted to the School of Economics, University of Nairobi, in partial fulfillment of the requirements for award of the degree of Masters of Arts in Economics, P 78.

P R Venugopal \& K Sudha (2017), Do macroeconomic variables influence Bombay Stock Exchange (BSE 30) stock prices in India?, IOSR Journal of Business and Management, PP 20-31.

Ray \& Sarkar (2014), Macroeconomic link to Indian capital market: A post-liberalization evidence, Modern Economy, 2014, 5, 272-288.

Saleh In'airat (2018), The effect of internal and external factors on stock market prices - evidence from Saudi Arabia, The Business and Management Review, Volume 9 Number 3, 413- 423.

Samontaray \& Nugali \& Sasidhar (2014). A Study of the Effect of Macroeconomic Variables on Stock Market: Saudi Perspective, International Journal of Financial Research, Vol. 5, No. 4; 2014

Venkatraja.B (2014), Impact Of macroeconomic variables on stock market performance in India: An empirical analysis, International journal of business quantitative economics and applied management research, Volume 1 , Issue 6, 71- 85 .

Zervos, Sara \& Levine, Ross (2000), capital control libiralization and stock market development; the W.B ploicyr search; working paper; Washington; 2000; p:15. 